\title{
Polar Phenolic Compounds in Peppermint Rhizomes and Leaves
} \\ Original Paper \\ Bittner Fialová S. ${ }^{1, \bigotimes}$, Harris Ch. ${ }^{2}$, Ordsmith V. ${ }^{2}$, Nagy M. ${ }^{1},{ }^{2}$ Jonáš F. ${ }^{3}$, Mučaji P. ${ }^{1}{ }^{1}$ \\ Department of Pharmacognosy and Botany, \\ Faculty of Pharmacy, Comenius University in Bratislava, \\ Odbojárov 10, 83232 Bratislava, Slovak Republic \\ ${ }^{2}$ Microsaic Systems plc, GMS House, Boundary Road, \\ Woking, Surrey, GU21 5BX, United Kingdom \\ ${ }^{3}$ Amedis spol. s.r.o., Kamenárska 7 , \\ 82104 Bratislava 2, Slovak Republic \\ Received 9 May, 2019, accepted 18 September, 2019
}

Abstract Peppermint belongs to one of most popular medicinal plants in pharmacy as well as in the food industry.

Aim: For the conventional usage, the aerial part, especially leaves, is used. This investigation was aimed at the determination of phenolic compound in peppermint rhizomes infusion and the comparison with the phenolics in leaves infusions.

Methods: For the separation and identification of the phenolic compounds, the Sykam HPLC-DAD connected with Microsaic $4500 \mathrm{MiD}^{\circledR}$, a single quadrupole mass spectrometer, was used.

Results: Three compounds in rhizomes and eight compounds in leaves were identified and quantified. In rhizomes, rosmarinic acid was determined as the main secondary metabolite, but its content was three times lower than that in leaves. Infusion of peppermint leaves was richer in flavonoids content with eriocitrin as a major phenolic compound.

Conclusion: Rhizomes of peppermint may also be used as a potential source of rosmarinic acid and caffeic acid derivatives.

Keywords Mentha-Rhizomes-Leaves-HPLC-DAD-MS-single quadrupole-Rosmarinic acid

\section{INTRODUCTION}

The genus Mentha L. belongs to the large family of Lamiaceae, subfamily Nepetoidae. A lot is known about the usage of aerial parts, especially because of the menthol-rich essential oil and phenolic compounds such as rosmarinic acid and eriocitrin. Peppermint has been reported to possess many biological activities, for example, digestion-stimulating, choleretic, antiseptic, secretolytic, antibacterial, antiviral, antispasmodic, antioxidant, anti-inflammatory, myorelaxant, and analgesic effects (Mckay \& Blumberg, 2006; Lawrence, 2007). The use of mints is mostly due to the presence of two groups of secondary metabolites: essential oil components (monoterpenes, sesquiterpenes) and phenolic compounds (flavonoids and phenolic acids) (Mimica-Dukic \& Bozin, 2008). Less is known about peppermint rhizomes, which are produced in high quantity every year (Fialova et al., 2012). The aim of this study was to compare the leaves and rhizomes of peppermint from the side of phenolic compounds using Sykam HPLC-DAD connected with the Microsaic 4500 MiD $^{\circ}$ mass spectrometer.

\section{MATERIALS AND METHODS}

Leaves and rhizomes of Mentha piperita were collected from the Medicinal Plant Garden of the Faculty of Pharmacy, Comenius University in Bratislava. Leaves were collected at the flowering time and rhizomes in spring. The plants were dried in the drying room at $30-32{ }^{\circ} \mathrm{C}$.. Voucher specimens are deposited at the Department of Pharmacognosy and Botany, Faculty of Pharmacy, Comenius University in Bratislava, Slovakia.

Infusions of dried leaves or rhizomes of M. piperita L. were prepared according to Pharmacopoeia Bohemoslovaca 4th edition (PhBs IV, 1987). Each infusion was lyophilized separately. For the HPLC analysis, $5 \mathrm{mg}$ of lyophilizate was dissolved in $1 \mathrm{~mL}$ of water of HPLC quality.

\section{Qualitative analysis by HPLC-DAD-MS}

The HPLC-DAD analyses were performed using an HPLC system (Sykam, Eresing, Germany) equipped with a pump 
Table 1: Phenolic compounds in lyophilizates of rhizomes and leaves of peppermint.

\begin{tabular}{|c|c|c|c|c|}
\hline Plant part & Compound & RT (Sykam) & [M-H] $\mathbf{~ / ~} \mathbf{z}$ & Identified/proposed Structure \\
\hline Peppermint rhizomes & 1 & 29.7 & 609 & Hesperetin-7-O-rutinoside (hesperidin) \\
\hline & 2 & 30.6 & 359 & Rosmarinic acid \\
\hline & 3 & 32.1 & 717 & Caffeic acid tetramer \\
\hline & & & & Eriodictyol-7-O-rutinoside (eriocitrin) \\
\hline Peppermint leaves & 1 & 25.9 & 595 & Luteolin-7-O-rutinoside \\
\hline & 2 & 26.5 & 593 & Luteolin-7-O-glucuronide \\
\hline & 3 & 27.6 & 461 & Apigenin-7-O-rutinoside (isorhoifolin) \\
\hline & 4 & 28.6 & 577 & Caffeic acid tetramer (salvianolic acid B?) \\
\hline & 5 & 29.3 & 717 & Hesperetin-7-O-rutinoside (hesperidin) \\
\hline & 6 & 29.6 & 609 & Rosmarinic acid \\
\hline & 7 & 30.6 & 359 & Caffeic acid tetramer \\
\hline & 8 & 32.2 & 717 & \\
\hline
\end{tabular}

$R T$, retention time.

(S1125), an autosampler (S5250), a column oven (S4120), PDA detector (S3345), and Clarity Software. The HPLC system was connected in a series to mass spectrometer $4500 \mathrm{MiD}^{\circ}$ (Microsaic Systems plc, Woking, the UK), a single quadrupole with a mass range of $1400 \mathrm{~m} / \mathrm{z}$ equipped with ESI source (spraychip $\left.{ }^{\circ}\right)$. HPLC separation of the peppermint leaves or rhizomes lyophilizate was carried out on a TELOS LU C18 (2), 250x4.6 mm ID, 5um (KINESIS, Cheshire, the UK), at a temperature of $30^{\circ} \mathrm{C}$ and a flow rate of $0.8 \mathrm{~mL} / \mathrm{min}$. Water ( $\mathrm{pH} 2.59$ with HOAc, Merck, Germany) and MeCN (MS grade, Honeywell, Riedel-de-Haen, Seelze, Germany) were used as mobile phase $A$ and $B$, respectively. The following gradient program was used: 10\% B (0 min), 15\% B (10 min), 30\% B (20 min), 40\% B (40 min), 90\% B (45 min), and 10\% B (50 $\mathrm{min})$, followed by a column cleaning and re-equilibration step (Fialová et al., 2015). The MS parameters were given as follows: negative ion mode, tip voltage, $-750.0 \mathrm{~V}$; nebulizer flow, 2,500.0 ml min-1; vacuum interface voltage, $40.0 \mathrm{~V}$; tube lens voltage, $10.0 \mathrm{~V}$; plate lens voltage, $5.0 \mathrm{~V}$; ion guide voltage, $1.0 \mathrm{~V}$; count time, $0.08 \mathrm{~ms}$; and Software Masscape. $\mathrm{N}_{2}$ was used as a nebulizing gas.

\section{Quantitative determination of constituents by HPLC- DAD}

The quantitative determination of phenolic compounds in Mentha leaves or rhizomes lyophilizates was provided by the method of external standards. The compounds in infusions were measured at two different wavelengths (280 and 320 $\mathrm{nm}$ ). We used rosmarinic acid for the quantification of both the compounds and caffeic acid derivatives, eriocitrin, and hesperidin for the quantification of flavonoid glycosides (see Table 2). Chromatographic standards for rosmarinic acid and hesperidin were purchased from Sigma-Aldrich (St. Luis, USA) and for eriocitrin were purchased from HWI pharma service (Rülzheim, Germany). The calibration curves of rosmarinic acid were prepared at $320 \mathrm{~nm}$, whereas those of eriocitrin and hesperidin were prepared at $280 \mathrm{~nm}$. The calibration curves were obtained by injection of known concentrations (5 - 100 ppm). All three standards showed good linearity. The following $r^{2}$ values were obtained: for eriocitrin, $r^{2}=$ 0.9999 and regression curve $y=7.7359 x$; for hesperidin, $r^{2}$ $=0.9997$ and regression curve $y=8.8442 x-0.3869$; and for rosmarinic acid, $r^{2}=0.9998$ and regression curve $y=17.805 x+$ 16.698. For eriocitrin, LOD was $1.31 \mu \mathrm{g} \cdot \mathrm{mL}^{-1}$ and LOQ was 3.97 $\mu \mathrm{g} \cdot \mathrm{mL}^{-1}$. For hesperidin, LOD was $2.28 \mu \mathrm{g} \cdot \mathrm{mL}^{-1}$ and LOQ was $6.92 \mu \mathrm{g} \cdot \mathrm{mL}^{-1}$. For rosmarinic acid, LOD was $1.92 \mu \mathrm{g} \cdot \mathrm{mL}^{-1}$ and $\mathrm{LOQ}$ was $5.81 \mu \mathrm{g} \cdot \mathrm{mL}^{-1}$. The results were expressed in $\mu \mathrm{g} \mathrm{mL}^{-1}$ of water infusion. The examinations of secondary metabolites in mint rhizomes and leaves lyophilizates were performed in triplicate. The quantitative results were calculated from calibration curves, expressed as mean values and standard deviation (SD).

\section{RESULTS AND DISCUSSION}

Aerial parts of mints are used in food as well as traditional and conventional medicines all over the world. The most famous species is unambiguously the peppermint, aided by the menthol content in essential oil. Secondary metabolites are also important contributors of peppermint usage. Lyophilizates of the aerial part of peppermint are rich in phenolics such as rosmarinic acid, eriocitrin, luteolin glycosides, apigenin glycosides, and caffeic acid derivatives. All of these compounds influence the medicinal properties of peppermint extracts (dry or liquid). The major compounds 


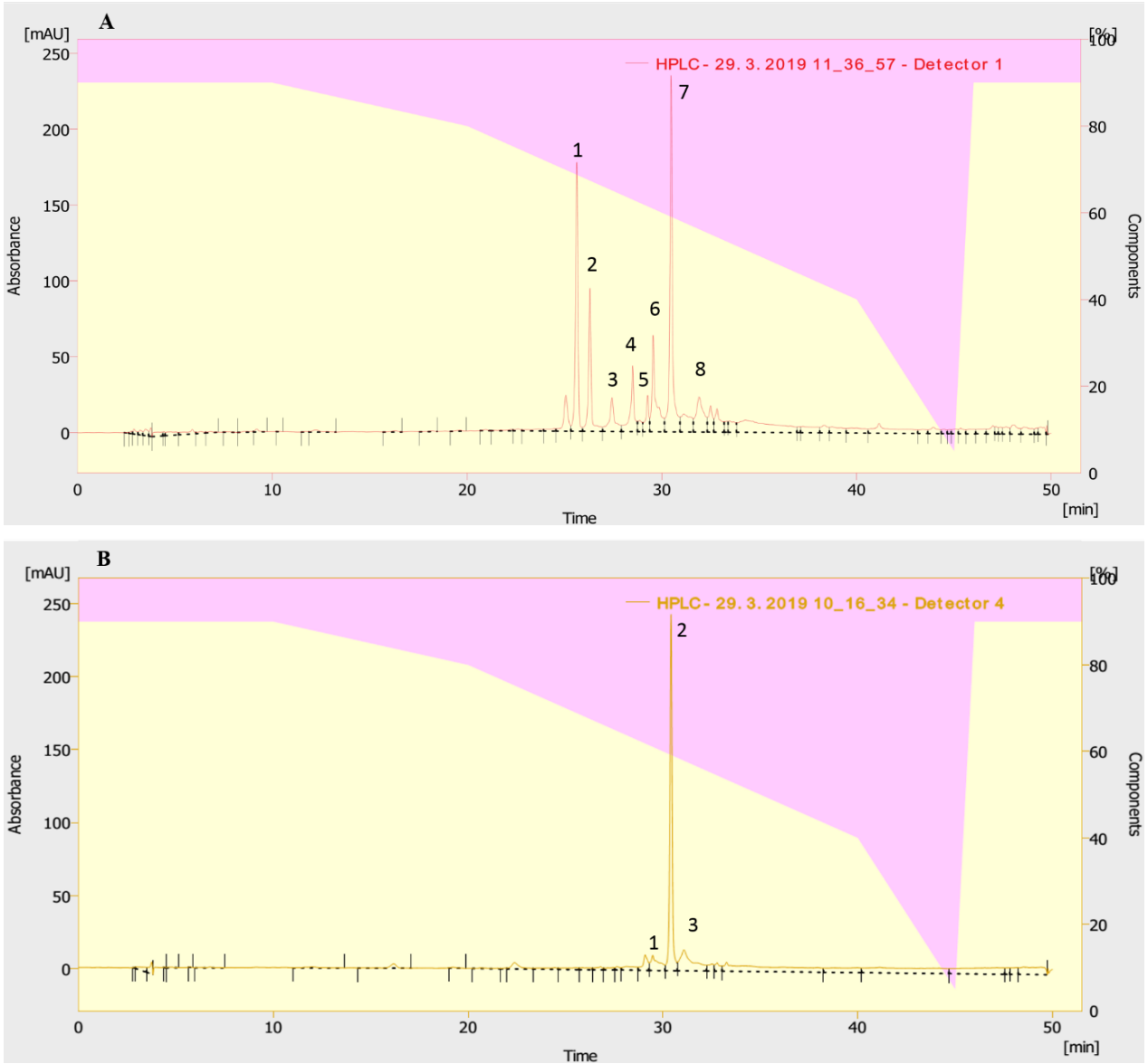

Figure 1: (A) HPLC-DAD chromatogram of peppermint leaves infusion $(\lambda=280 \mathrm{~nm})$; (B) HPLC-DAD chromatogram of peppermint rhizomes infusion $(\lambda=320 \mathrm{~nm})$.

Table 2: Quantitative abundance of polar phenolic compounds in infusions of M. piperita rhizomes and leaves $\left(\mu \mathrm{g} \cdot \mathrm{mL}^{-1}\right)$.

\begin{tabular}{|c|c|c|}
\hline \multirow{2}{*}{ Compounds } & \multicolumn{2}{|c|}{ Mass concentration $\left(\mu \mathrm{g} \cdot \mathrm{mL}^{-1}\right) * \pm \mathrm{SD}$} \\
\hline & Rhizomes & Leaves \\
\hline Eriodictyol-7-O-rutinoside (eriocitrin) ${ }^{\mathrm{a}}$ & - & $349.5 \pm 10.52$ \\
\hline Luteolin-7-O-rutinoside ${ }^{a}$ & - & $204.1 \pm 9.02$ \\
\hline Luteolin-7-O-glucuronide ${ }^{a}$ & - & $58.8 \pm 0.77$ \\
\hline Apigenin-7-O-rutinoside (isorhoifolin) ${ }^{a}$ & - & $59.1 \pm 3.88$ \\
\hline Caffeic acid tetramer (salvianolic acid B?) ${ }^{c}$ & - & $24.1 \pm 3.08$ \\
\hline Hesperetin-7-O-rutinoside (hesperidin) ${ }^{\text {b }}$ & $19.8 \pm 2.48$ & $37.47 \pm 3.02$ \\
\hline Rosmarinic acid ${ }^{c}$ & $93.8 \pm 8.15$ & $286.4 \pm 5.69$ \\
\hline Caffeic acid tetramer ${ }^{c}$ & $7.99 \pm 1.61$ & $25.0 \pm 1.48$ \\
\hline
\end{tabular}

*Values $\left(\mu \mathrm{g} \cdot \mathrm{mL}^{-1}\right.$ in liquid extract) are presented as means \pm standard deviation $(n=3)$, calculated as external standards: aeriocitrin, bhesperidin, crosmarinic acid.

are eriocitrin and rosmarinic acid (Areias et al., 2001; Dorman et al., 2009). The question was if the underground parts are also rich in these compounds and in what amounts. Recently, we found out that the antioxidant activities of leaves and rhizomes are comparable (Fialová et al., 2012). Using liquid chromatography connected to $4500 \mathrm{MiD}^{\circ}$ mass spectrometer, the separation and identification of phenolic compounds of Mentha leaves and rhizomes lyophilizates was performed (see Table 1). Three phenolic compounds in rhizomes and eight in leaves samples were identified by comparison with authentic standards and/or literature. The resolution of caffeic acid tetramer (leaves: peak 6) was not clear. Anyways, we suggest 
according to literature and previous analyses that peak 6 could be identified as salvianolic acid B. All compounds have been described previously in the genus Mentha L. (Areias et al., 2001; Dorman et al., 2009; Dorman et al., 2003; Fialová et al., 2009).

The quantitative analysis was performed using the HPLC-DAD by the method of external standards (eriocitrin, hesperidin, and rosmarinic acid). The results are displayed in Figure 1 and Table 2. Mint's rhizomes are not as rich in phenolic compounds as its leaves. The major compound in rhizomes' infusion was rosmarinic acid $\left(93 \mu \mathrm{g} \cdot \mathrm{mL}^{-1}\right)$, but its content was three times lower than that in leaves $\left(286 \mu \mathrm{g} \cdot \mathrm{mL}^{-1}\right)$. As in previous studies, eriocitrin (eridictyol-7-O-rutinoside) was identified as the main phenolic compound in the infusion of peppermint leaves.

\section{CONCLUSIONS}

By using the HPLC-DAD connected to MS (4500MiD', a single quadrupole) we analyzed the infusions of peppermint leaves and rhizomes. We identified and quantified one flavonoid and two caffeic acid derivatives in rhizomes and five flavonoid glycosides and three caffeic acid derivatives in leaves. The main component in rhizomes is the phenolic compound rosmarinic acid. Despite of its three times lower content than that in leaves, rhizomes may be considered as a potential source for pharmaceutical research and for use in the food industry. It could be beneficial to prepare and study other kinds of peppermint rhizomes extracts (also non-polar).

\section{ACKNOWLEDGMENTS}

This work was supported by the Grant Agency of Ministry of Education, Science, Research, and Sport of the Slovak (grant no. VEGA-1/0290/16) and by the Slovak Research and Development Agency under the contract No. APVV-15-0123.

\section{CONFLICTS OF INTEREST}

The authors declare no conflict of interest.

\section{References}

[1] Mckay DL, Blumberg JB A review of the bioactivity and potential health benefits of peppermint tea (Mentha $\times$ pipretia L). Phytother Res. 2006;20:619-633.

[2] Lawrence BM. Mint. The genus Mentha. Medical and Aromatic Plants -Industrial Profiles. Volume 44. CRC Press, Taylor \& Francis Group, Boca Raton, London, New York 2007.

[3] Mimica-Dukic N, Bozin B. Mentha L. species (Lamiaceae) as promising sources of bioactive secondary metabolites. Curr Pharm Des. 2008;14:3141-3150;

[4] Fialova S, Tekel'ová D, Grančai D. The content of phenolic compounds in underground and aerial parts of different Mentha species. Acta Fac Pharm Univ Comen. 2012;59:30-38.

[5] Pharmacopoea Bohemoslovaca PhBs IV. Avicenum, Praha. 1987

[6] FialováS,SlobodníkováL,VeizerováL,GrančaiD.Lycopuseuropaeus: phenolic fingerprint, antioxidant activity and antimicrobial effect on clinical Staphylococcus aureus strains. Nat Prod Res. 2015;29:2271-2274, DOI: 10.1080/14786419.2015.1010086.

[7] Areias FM, Valentao P, Andrade PB, Ferreres F, Seabra RM. Phenolic fingerprint of peppermint leaves. Food Chem. 2001;73:307-311.

[8] Dorman DJH, Kosar M, Kahlos K, Holm Y, Hiltunen K. Phenolic Profile and antioxidant evaluation of Mentha $\times$ pipretia L. (peppermint) extracts. Nat Prod Commun. 2009;4:535-542.

[9] Dorman HJD, Kosar M, Kahlos K, Holm Y, Hiltunen R. Antioxidant properties and composition of aqueous extracts from Mentha species, hybrids, varieties, and cultivars. J Agric Food Chem. 2003;51:4563-4569;

[10] Fialová S, Prinz S, Zehl M, Tekel'ová D, Reznicek G, Grančai D, Kopp B. Polyphenolic fingerprint of methanolic extracts of Mentha sp. cultivated in Slovakia. Planta Med. 2009;75:SL24. 